\title{
Research on the Loss of Cultural Information of Idiom Translation
}

\author{
Li Liu \\ School of Foreign Languages, Zhengzhou University of Industrial Technology, Zhengzhou 451150, \\ China
}

625960018@qq.com

Keywords: idioms translation, cultural differences, cultural loss.

\begin{abstract}
In recent years, with expanding openness and inter-cultural communication with western countries, the cultural perspective in translation has gradually become the focus of research. On the one hand, the mistranslation caused by idioms, especially the misunderstanding and conflict, is a problem of communication. On the other hand, the loss of source language in intercultural translation is widespread.
\end{abstract}

\section{Introduction}

Eugene Nida points out that translation is the communication between two cultures. For truly successful translation, being familiar with two cultures is even more important than mastering two languages in a way because idioms usually have special meaning and stories related with their native culture. Thus, it's impossible to achieve effective communication between two cultures when idiom translation disconnects with cultural background.

Currently studies about idiom translation in the perspective of culture mostly focus on the differences between Chinese and Western culture and translation skills. Chen Guanghong (2010) analyses cultural factors from the geographical environment, proverbs, and value; Xing Chunyan (2006) discusses the idioms in general, including idioms, proverbs, allusions, etc. in "the cultural differences between English and Chinese idioms and translation”. These articles study idioms basically from the perceptive of comparative culture and cultural differences.

\section{Reasons for Cultural Loss in the Translation of Idioms}

The reasons causing the loss of cultural information in the process of cross-cultural translation are various, which can be analyzed from two aspects: subjective factors and objective ones. Subjective factors mainly refer to contextual understanding deviation and poor cultural knowledge and language skills. Objective factors emphasizes on the influence of cultural erosion.

\subsection{Negative Transfer of Culture}

Negative transfer of culture refers to the cultural interference caused by cultural differences, which usually appears in the intercultural communication and foreign language learning. People consciously apply native cultural norms and values to guide their behaviors and thoughts, and take this as a standard to understand the words and ideas of others. Negative transfer of culture, in other words, refers to the mode of mother tongue culture which is not properly applied to the interpretation of the cultural phenomenon in target language. Negative transfer of culture often leads to cross-cultural communication barriers, misunderstanding and even cultural conflicts.

\subsubsection{Conflicts of Words}

Conflicts of words refer to the contradictory cultural information contained in the source language words and the target language words. The literal meaning of the words seems to be the same, but the underlying cultural information the words convey is quite different or even opposite. For example, Chinese culture is group orientated and values collectivism, while western culture is the individual orientated and values individualism. University of Webster's dictionary defines it as: "individual personality and economic independence emphasize individual initiation, action and interesting theory, and the practice under the guidance of this theory." And modern Chinese explains it as the selfish 
ideas that do everything out of personal interests, put individual interests above collective interests, and disregard for others. Due to cultural differences, the individualism in western societies is a commendatory term, which is a derogatory term in Chinese. So, in the cultural concept of Chinese and westerners in understanding individualism is under the condition of serious conflict. Therefore, in idiom translation, the profound cultural connotation should not be ignored.

\subsubsection{Word Association}

Due to different cultural atmosphere and the influence of the natural ecological environment, people from different ethnics may have different emotional reactions or semantic association for the same natural phenomenon, the same thing, the same color, etc., which constitute another obstacle of idiom translation. For example, Chinese character "eight" usually gives the association of "getting rich" because it is homophone for "fa" which means "getting rich". While the corresponding English word eight cannot give American and British people the similar associations. In addition, Chinese people see the goat as nothing but an honest and docile animal, while it has the association of satyr in English. Words have different meaning in specific context, and cultural image is established in cultural cognitive schemata in different nation or community.

\subsection{Cultural Vacancy}

In Chinese-English translation, due to cultural differences, equivalent words in the target language are not available in describing some unique cultural phenomena, which will result in vocabulary vacancy and lead to the loss of cultural information in the process of translation. The same thing can be expressed clearly by using a single word in one language, but beating around the bush in other languages. Translators who have little knowledge about vocabulary vacancy will inevitably face with intercultural communication difficulties and the translation obstacles.

Cultural vacancy phenomenon was firstly found by the American linguist Mr. Kate in the 1950s. He put forward the concept of accidental gaps by comparing the grammatical patterns of the two languages. In the late 80s, Russian scholars Solo Gold and others proposed the theory of vacancies in discourse and its national culture characteristic. Language, as the carrier of culture, reflects the colorful ethnic cultural forms and rich variety of cultural phenomenon. Due to the geographical, social development and the influence of religious culture, Chinese and Westerners have each own ideology, values, customs and way of thinking which tend to vary wildly, thus cultural gap often appears in the case.

For example, "ban men nong fu"( display one's poor skill before an expert) is a special idiom in China, but there are few people who know the famous ancient Chinese craftsman Lu Ban in Englishspeaking countries, which causes cultural vacancy. If it is directly translated into "to show off one's proficiency with the ax before Lu Ban”, it may make the people in English countries confused. If the corresponding expressions in English "to off/call a fish how to swim” or "to call one's grandmother how to suck dense eggs" are applied to the translation, the cultural information in the original Chinese idiom is lost. So the better way to solve the problem is to follow concise and fluent liberal translation with further explanation of the origin of the idiom.

\subsubsection{Differences in Living Environment}

In the process of work and life idioms are formed gradually in the national language. As an ancient island country, British people are good at fishing and navigation, and the two industries occupy an important position in its economic life. Therefore, there are many figurative idioms associated with fishing and sailing in English language. For example, "fish in the troubled water", "as dumb as a fish", "drink like a fish", "never offer to teach fish to swim”, "catch a crab” etc. while the Chinese lives in the vast Asia continent, and the features of inner land life are also reflected in language. For instance, "money" is compared to "dust" to describe the large amount a person squanders in Chinese idiom, but it is compared to "water" in English idiom.

With vast land and various climate, Chinese use “dongfeng”(east wind) representing "spring”. Britain is located in the North Temperate Zone, temperate maritime climate characteristics, so commonly use "west wind" describing "spring". In Britain, the summer there is different from the Asian continent, the seasonal weather is very warm, so this season often associates with "cute", 
"good", "moderate", etc. A famous poet assimilate "lover" to "summer", for example, "Shall I compare thee to summer's day?"

\subsubsection{Different Ways of Thinking}

As a result of living in different social environment, sometimes there are differences in concept between English and Chinese people, even completely opposite views to the same thing. Take the attitude to the treatment of animals as an example. Dogs are usually associated with derogatory sense in Chinese idioms, such as, "brutal and cold blooded", "a coward” and so on. But, in English language, dogs are seen as human's loyal partner. Unlike Chinese English idioms related to dogs are commonly used without such derogatory sense, such as “a lucky dog”, "a guy dog”.

\subsubsection{Different Religious Beliefs}

Both English and Chinese languages contain a large number of idioms related to religious belief. Over two thousand years ago, Buddhism was introduced into China, after that, with wide accept of Buddhism, a large number of idioms about Buddhism appeared, such as "Buddha tenant Zen”, "Buddha nature" and so on. But in Britain, Christianity is the major religion of the sect, and there are also many related idioms, such as "God help those who help more”, "Go to hell”.

\section{Strategies of Cultural Loss in Cross-cultural Translation}

Translation is a kind of bidirectional cultural activities. The difficulty lies not only in the simple conversion between two languages or multiple languages, but also in how to keep the source cultural characteristics in the conversion.

\subsection{Deep Understanding of Chinese and English Culture}

With increasing international exchanges and cooperation, people pay more and more attention to the cultivation of intercultural communicative competence in English learning. Cross-cultural communication refers to communication between people of different cultural backgrounds. Culture is the center of the cross-cultural communication research. The process of learning English is to know and master the process of English national culture. If English learners just pour energy in language form, and ignore the social and cultural knowledge in language, it will lead to the lack of the understanding of Chinese and western cultural differences. In practical use, although the translation is correct in grammar, it may also lead to cultural conflicts and result in communication failure. Therefore, it is of great significance to understand differences between Chinese and western culture. Thus a deep understanding of Chinese and English culture is helpful to precise and effective idiom translation.

Chinese traditional way of thinking is used to understanding things and the world as a whole, which contains not only the scientific nature and rationality, but traditional speculative philosophy and unscientific components. In translation, we should retain a overall observation of the strengths of things, at the same time, strongly absorb western level analysis, empirical analysis, inductive synthesis and logical thinking of the scientific method, and practice understanding and analysis of comprehensive logical thinking proposed for the scientific development to deal with the relationship between man and nature, individual and society, etc.

China's feudal society has been going on for thousands of years. Taoism, Confucianism and Buddhism culture are intertwined. Traditional psychology tends to be conservative, such as "look before you leap”. Such consciousness severely fetters people's thought and behavior, hinders the development of personal ability, and suppresses people's subjective initiative and creativity. Western culture has formed a competitive innovation due to the influence of the commodity economy, free trade, and developing the overseas market. And the development of the capitalist market economy has brought vitality.

Understanding the differences between Chinese and western culture is of great significance to improve the ability of intercultural communication, and it can help us to correctly understand the words and deeds of westerners in the process of communication, fully understand and respect each other, and achieve the best effect of communication. Chinese and western cultures have their own strengths and can be compatible in some aspects, so we should adopt a positive attitude to absorb western civilization achievements, national development and prosperity of culture. 


\subsection{Strategies for Idiom Translation}

Duo to the uniqueness of different cultures, the loss of cultural information in idiom translation is unavoidable. The possible effort translators can make is to retain the original cultural information to the greatest extent. In translating, translators should fully understand the differences between Chinese and western culture and deepen the understanding of our own culture to improve our ability of crosscultural translation. In addition, translation strategies are also important.

Translation strategies should strive to reproduce the original style and features, as far as possible with no damage to the connotation of the original image and the content it conveys. If there are conflicts between two different cultural backgrounds, some translation strategies can be applied flexibly in idiom translation to avoid different language cultural dislocations. Domestication and alienation are effective strategies for translation, which can be applied in idiom translation by combination to reduce the loss of cultural information. Domestication is used as the main strategy with the complementary alienation. For idioms with cultural information which can't be liberally translated, translators should do cultural equivalence translation as far as possible by using some strategies to avoid cultural loss in cross-cultural translation.

\section{Summary}

Translation is difficult, and the difficulties lie in the real understanding and precise expression of cultural information in the idioms. There are both commonness and individuality between different cultures, so it is inevitable to cause the loss of cultural information in idiom translation. Translation is obviously not only the process of language transformation, but also a process of cultural integration. Generally speaking, pure language barriers can overcome easily, but the cultural obstacles are difficult to overcome. With the depth of opening deepens and breadth widens, China's communication with the world becomes much more frequent than any time. Idioms which carry a lot of cultural information play an important role in communication. Idiom translation is important for foreigners to know about the Chinese culture. The quality of idiom translation affects the success of the communication to a great extent.

\section{References}

[1]. Bassnett, S. Translation Studies. Shanghai: Shanghai Foreign Language Education Press, 2004.

[2]. Fernado, C. Idioms and Idiomaticity. Shanghai: Shanghai Foreign Language Education Press, 2000.

[3]. Hervey, S. \& I. Higgins. Thinking Translation, A Course in Translation Method:Frence and English. London: Routledge, 1992, 36-40.

[4]. Nida, E. A., \& Charles, T. The Theory and Practice of Translation. Shanghai: Shanghai Foreign Language Education Press, 2004.

[5]. Smaovar, L.A., Porter, R.E., \& Stefani, L.A. Communication between Cultures. Beijing: Beijing Foreign Language Teaching and Research Press, 2000. 